\section{PENGELOLAAN PERIKANAN KARANG DI TAMAN NASIONAL WAKATOBI: PERSPEKTIF AKTOR DAN AGEN}

Coral Fisheries Management in Wakatobi National Park Wakatobi Region: Actor and Agent Perspective

Oleh:

Mercy Patanda ${ }^{1}$, Sugeng H. Wisudo ${ }^{2}$, Daniel R. Monintja ${ }^{2}$, Budy Wiryawan ${ }^{2}$

1 Program Studi Teknologi Perikanan Laut, FPIK, IPB; patandamercy@gmail.com 2 FPIK IPB; wisudo@yahoo,com; danipb41@yahoo.com; bud@psp-ipb.org

Diterima: 25 Januari 20168 Maret 2017; Disetujui: 14 September 20164 April 2018

\section{ABSTRACT}

Stakeholders, who are agents and actors in this matter play an important role in the management of reef fisheries in Wakatobi National Park. This study aims to identify the agents and actors in Wakatobi Regency and to identify similarities and differences of the perception between agents and actors in the management of conservation areas. The method used is Principal Component Analysis (PCA). The result showed that there was a similar perception between agen and actor in which that the conservation gives benefit for the society in Wakatobi and the lack of regulation in Wakatobi Regency. Different perceptions between actors and agents occurred due to fishermen intention to fully utilize the resources for their welfare while the government intents to limit the fishing area in order to preserve the natural resources and the environment. Therefore, management related to the regulation on legal-size of fish and the effectiveness of marine protected areas are needed.

Keywords: Stakeholders, Coral Reef, Conservation, Wakatobi

\section{ABSTRAK}

Pemangku kepentingan sangat berperan penting dalam pengelolaan perikanan karang $d i$ Taman Nasional Kabupaten Wakatobi. Tujuan penelitian adalah mengidentifikasi agen dan aktor yang berada di Kabupaten Wakatobi serta melihat persamaan dan perbedaan persepsi antara agen dengan aktor dalam pengelolaan kawasan konservasi. Penelitian ini menggunakan analisis Principal Component Analysis (PCA). Hasil kajian menunjukkan adanya persamaan persepsi antara agen dan aktor yaitu konservasi memberikan manfaat bagi masyarakat yang ada di Wakatobi dan masih kurangnya peraturan di Kabupaten Wakatobi. Perbedaan persepsi pada aktor dan agen karena nelayan ingin memanfaatkan perairan Taman nasional Wakatobi semaksimal mungkin untuk kesejahteraan nelayan sedangkan pemerintah membatasi wilayah penangkapan dalam rangka menjaga sumber daya alam dan lingkungannya sehingga perlu tindakan pengelolaan yaitu penentuan ukuran ikan yang tertangkap dan pengefektifan daerah perlindungah laut.

Kata kunci: Pemangku Kepentingan, Perikanan Karang, Konservasi, Wakatobi
Formatted: Font: $12 \mathrm{pt}$, Not Superscript/ Subscript

Formatted: Font: 12 pt, Not Superscript/ Subscript

Formatted: Font: 12 pt, Not Superscript/ Subscript

Formatted: Font: 12 pt, Not Superscript/ Subscript

Formatted: Font color: Black, German (Germany)

Formatted: Font: Book Antiqua, 9 pt, Italic, Font color: Black, Not Superscript/ Subscript

Field Code Changed

Formatted: Font: Book Antiqua, 9 pt, Italic, Font color: Black, Not Superscript/ Subscript

Formatted: Font color: Black, German (Germany)

Formatted: Font: Book Antiqua, 9 pt, Italic, Font color: Black Not Superscript/ Subscript

Field Code Changed

Formatted: Font: Book Antiqua, 9 pt, Italic, Font color: Black, German (Germany), Not Superscript/ Subscript

Formatted: Font: Book Antiqua, 9 pt, Italic, Font color: Black, German (Germany), Not Superscript/ Subscript

\section{Field Code Changed}

Formatted: Font: Book Antiqua, 9 pt, Italic, Font color: Black, German (Germany), Not Superscript/ Subscript

Formatted: Font color: Auto

Formatted: Font: Arial, $10 \mathrm{pt}$, Italic

Formatted: Indonesian

Formatted: German (Germany) 


\section{PENDAHULUAN}

Taman Nasional Wakatobi memiliki potensi sumber daya dan keanekaragaman hayati laut yang tinggi dan salah satu diantaranya adalah ikan karang. Ikan karang yang menjadi target species nelayan adalah ikan karang konsumsi khususnya ikan karang hidup. Menurut Ramadhan et al. (2016) bahwa beberapa jenis ikan karang yang banyak diekploitasi oleh masyarakat pada saat survei di Wakatobi adalah ikan merah (Lutjanus biguttatus), baronang (Siganus guttatus), kakap lencam (Lethrinus $s p$.), dan kerapu (Epinephelus sp).

Pemerintah Kabupaten Wakatobi melibatkan stakeholder dalam perencanaan dan pengelolaan kawasan konservasi seperti pengembangan program konservasi terumbu karang serta pengembangan rencana pengelolaan sampai dalam tahap monitoring. Menurut $\mathrm{Ke}-$ putusan Menteri Kelautan dan Perikanan No 38 tahun 2004 tentang pedoman umum pengelolaan terumbu karang, pemangku kepentingan (stakeholders) adalah individu atau kelompok atau unsur masyarakat yang mempunyai kepentingan dalam suatu wilayah atau sumber daya yang terdapat dalam suatu wilayah.

Sistem kolaborasi telah terjadi antar stakeholder seperti perencanaan kawasan konservasi sampai pengelolaan kawasan konservasi. Stakeholder terdiri dari pemerintah dan non pemerintah. Pemerintah sebagai pemilik sumber daya alam yang disebut juga agen, sedangkan masyarakat yang memanfaatkan sumber daya alam disebut sebagai pelaku atau aktor seperti masyarakat.

Pemerintah menyadari Taman Nasional Wakatobi tidak hanya dapat dikelola oleh pemerintah saja tetapi dibutuhkan kerjasama dengan masyarakat untuk mendukung program pemerintah dalam melestarikan sumber daya dan lingkungannya sehingga program pemerintah itu dapat berjalan dengan baik. Salah satu kerjasama yang dilakukan antar stakeholder adalah melalui forum komunikasi. Forum komunikasi yang ada di Desa Mola Pulau Wangiwangi dalam bentuk kelompok nelayan seperti kelompok nelayan ikan karang kedo-kedo, ikan karang mitra sunu dan ikan tuna. Kelompok tani tersebut bermitra dengan lembaga swadaya masyarakat (LSM) atau pemerintah (DKP). Selain itu, menurut Hasrawaty (2016) Kabupa ten Wakatobi memiliki kearifan lokal yang melibatkan stakeholder yaitu Tuba dikakatuang dan Parika. Tuba dikakatuang memiliki arti kata "karang yang disayang" yang berisi kesepakatan dalam melindungi kawasan konservasi. Adapun arti kata parika yaitu tradisi dalam $\mathrm{su}_{-}$ ku bajo memilih ketua komunitas yang memim. pin kelompok nelayan yang memiliki kemampu an dalam menentukan waktu pemasangan alat ataupun ukuran alat tangkap yang digunakan Kolaborasi antara pemerintah dan ma-syarakat terjadi selama ini. Akan tetapi ditemu-kan persamaan dan perbedaan antara pemerintah (agen) dan non pemerintah (aktor) sehingga perlu dilakukan penelitian. Tujuan penelitian tersebut adalah untuk mengidentifikasi agen dan aktor yang berada di Kabupaten Wakatobi serta melihat persamaan dan perbedaannya dalam pengelolaan perikanan karang di kawasan konservasi.

\section{METODE}

Penelitian dipusatkan di Pulau Wangiwangi Kabupaten Wakatobi Sulawesi Tenggara (Gambar 1) karena Pulau Wangi-wangi merupakan kawasan konservasi, pusat pemerintahan dan pusat perdagangan ikan karang di Kabupaten Wakatobi. Penelitian dilaksanakan pada bulan Oktober 2015 sampai tahapan

\begin{tabular}{|l} 
Formatted: Indonesian \\
Formatted: Indonesian \\
Formatted: Indonesian \\
\hline Formatted: Indonesian \\
Formatted: Indonesian \\
\hline Formatted: German (Germany) \\
\hline Formatted: Indonesian \\
\hline Formatted: Indonesian \\
\hline Formatted: Indonesian \\
\hline Formatted: Indonesian \\
\hline Formatted: Indonesian \\
\hline Formatted: Indonesian \\
\hline Formatted: Indonesian \\
\hline
\end{tabular}

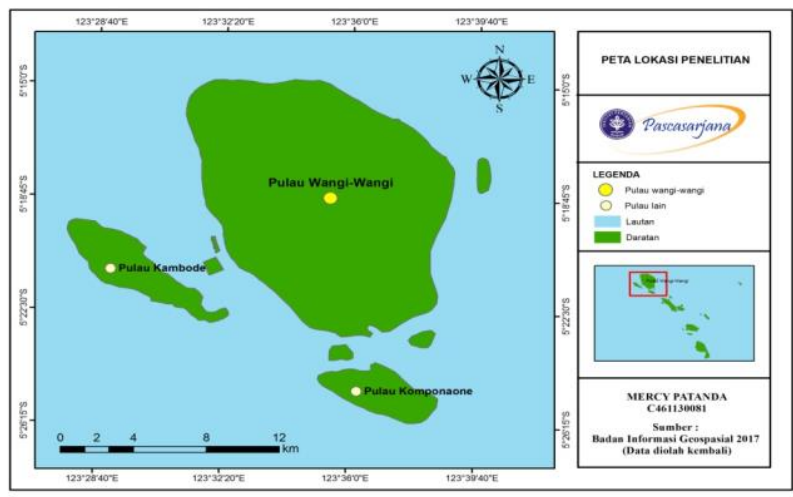

Gambar 1 Lokasi penelitian

Formatted: Indonesian

Formatted: Indonesian

Formatted: Indonesian

Formatted: Indonesian 
yaitu pembuatan kuesioner, pemilihan responden, interview responden dan menganalisis data primer.

Data yang dikumpulkan terdiri dari data primer yang terdiri dari ukuran ikan, lingkungan dan peraturan pemerintah sedangkan data sekunder yang terdiri dari sumber daya hayat Kabupaten Wakatobi dan peraturan pemerintah. Data primer dikumpulkan dari hasil wawancara dengan stakeholder yang terbagi, atas dua yaitu aktor dan agen. Data sekunder diperoleh dari berbagai literatur yang telah dipublikasikan seperti karya ilmiah dan laporan dari instansi $d$ Kabupaten Wakatobi. Pemilihan responden ditentukan secara sengaja dengan tetap mempertimbangkan posisi dan peran mereka dalam kegiatan sehari-hari atau disebut dengan pur posive sampling (Mujio et al. 2016). Responden terdiri dari pemerintah (Kementerian Kelautan dan Perikanan (KKP) di Kabupaten Wakatobi, Dinas Kelautan dan Perikanan (DKP) Kabupaten Wakatobi, Pemerintah Daerah (PEMDA) Kabupaten Wakatobi, nelayan, staf restoran dan lembaga swadaya masyarakat (LSM) yang berjumlah 72 orang dan masing-masing kelompok stakeholder berjumlah 18 dengan varias umur, latar belakang pendidikan, jabatan dalam pekerjaan, dan status pekerjaannya yang terlibat dalam perikanan karang dan pengelola $\mathrm{Ta}$ man Nasional Wakatobi. Pemilihan responden tersebut didasarkan stakeholder yang terlibat dalam pengelolaan dan rantai pemasaran ikan karang konsumsi di Kabupaten Wakatobi.

Data primer dianalisis dengan analisis multivariate dan analisis tersebut membantu dalam interpretasi matriks data yang kompleks. Analisis data yang digunakan menggunakan Principal Component Analysis (PCA). Kelebihan Principal Component Analysis (PCA) adalah memberikan cara yang obyektif untuk menemu kan indeks jenis parameter baru ini sehingga variasi dalam data dapat dipertanggungjawabkan (Shrestha dan Kazama 2007). Beberapa langkah dari analisis adalah

1. Input data primer yang merupakan hasi wawancara dengan responden dan perta-

Tabel 1 Responden dan klasifikasi diskriminant

\begin{tabular}{clcc}
\hline No & Responden & Jumlah Responden & Klasifikasi Diskriminant \\
\hline 1 & Nelayan & 18 & 100 \\
2 & Staf Restoran & 18 & 55 \\
3 & Staf Pemerintah & 18 & 100 \\
4 & LSM & 18 & 61,1 \\
\hline & & Ketepatan Klasifikasi & $79,2 \%$ \\
\hline
\end{tabular}

nyaan dari kuesioner yang terdiri dari peraturan berlaku di Kabupaten Wakatobi, ukur an ikan yang diminati dan lingkungan di ka wasan konservasi Wakatobi.

2. Proses analisis data yaitu menggunakan analisis diskriminant yang terdiri dari eigen nilai, standarisasi dari koefisien fungsi, klasifikasi hasil dan membuat screen plot

3. Hasil analisis data yang menunjukkan apakah diskriminan telah mengelompokkan stakeholder dengan benar dan prediksi dari axis.

4. Informasi yang diperoleh dari analisis data yaitu memperlihatkan persepsi antara stakeholder yang sama dan stakeholder yang berbeda.

\section{HASIL DAN PEMBAHASAN}

Perspektif antara agen dan aktor dengan menggunakan discriminant score seperti terlihat pada Tabel 1 dan Gambar 27. Adapuh perbandingan axis 2 dan axis 3 terhadap axis 1 disajikan pada Gambar 32 .

Tabel 1 memperlihatkan klasifikasi diskr minant memiliki tingkat klasifikasi lebih besar $79,2 \%$ yang berarti fungsi diskriminan mampu mengelompokkan stakeholder dengan benar dan hasil analisis dapat menggambarkan stake holder di Pulau Wangi-wangi.

Hasil analisis discriminant memperlihatkan bahwa aktor (LSM dan staf restoran) memiliki pendapat yang sama yaitu masih kurang peraturan pemerintah. Peraturan yang masih kurang yaitu ukuran ikan yang layak tangkap di Kabupaten Wakatobi karena selama ini hanya UD Pulau Mas yang menerapkan aturan penerimaan ikan minimal 600 gram.

Permasalahan yang sama antara agen dan aktor yaitu masih ditemukan penangkapap ikan dengan bius dan bom, penambangan pa sir serta penambangan karang. Kegiatan tersebut dapat memberikan dampak terhadap ling.
Formatted: German (Germany)

Formatted: Font: Not Bold, German (Germany)

Formatted: Font: Not Bold, German (Germany)

Formatted: German (Germany)

Formatted: Indonesian

Formatted: Indonesian

Formatted: Indonesian

Formatted: Indonesian

Formatted: Indonesian

Formatted: German (Germany)

Formatted: Indonesian

Formatted: Indonesian

Formatted: Indonesian

Formatted: Indonesian

Formatted: Indonesian

Formatted: Indonesian

Formatted: Indonesian

Formatted: Indonesian

Formatted: Indonesian

Formatted: Indonesian

Formatted: Indonesian

Formatted: Indonesian

Formatted: Indonesian

Formatted: Indonesian

Formatted: Indonesian

Formatted: Indonesian

Formatted: Indonesian

Formatted: Indonesian

Formatted: Indonesian

Formatted: Indonesian

Formatted: Indonesian

Formatted: Indonesian

Formatted: Indonesian

Formatted: Indonesian

Formatted: German (Germany)

Formatted: German (Germany)

Formatted: German (Germany)

Formatted: German (Germany)

Formatted: German (Germany)

Formatted: Indonesian 


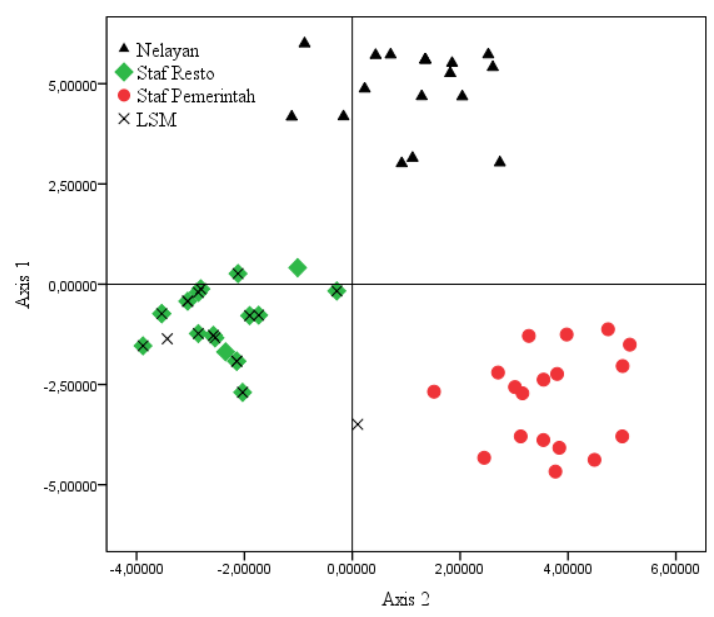

Gambar 1 2_ Klasifikasi responden berdasarkan fungsi diskriminan
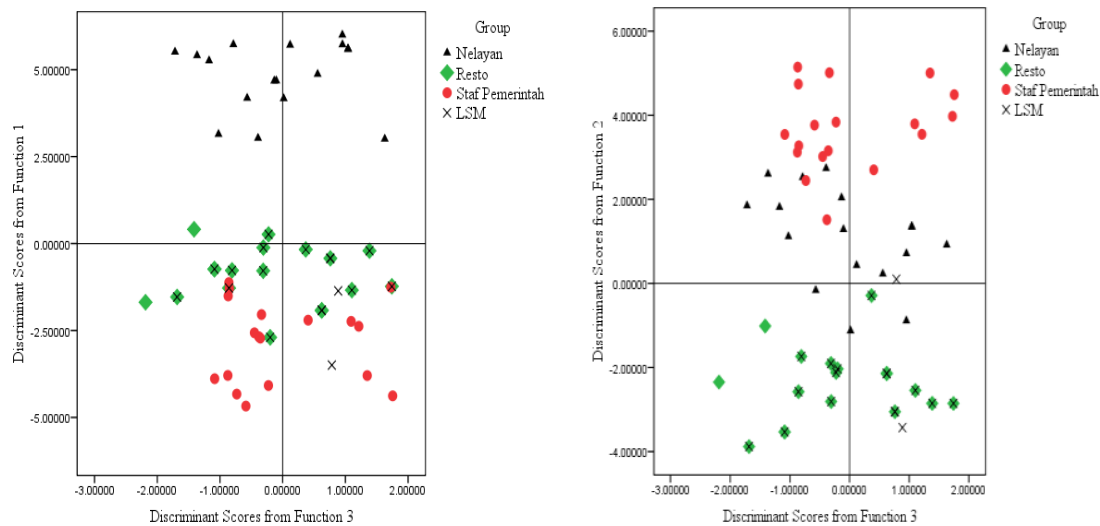

Gambar $2 \underline{3}$ Perbandingan klasifikasi responden berdasarkan diskriminan 2,3,1

kungan seperti kerusakan terumbu karang. Hal nelayan. Menurut Sopari et al. (2014), kegiatan tersebut umumnya dilakukan oleh nelayan pen_- yang berpotensi untuk dikolaborasikan di Kabudatang dan beberapa nelayan Kabupaten Wa- paten Wakatobi adalah kegiatan penanganan katobi. Sopari et al. (2014) menemukan perma- kasus, patroli pengamanan, penyuluhan/sosialisalahan yang sama di Kabupaten Wakatobi ya- sasi peraturan, monitoring sumber daya alam, itu masih terjadinya kegiatan illegal fishing, des- maupun pengelolaan wisata dan perijinan pertructive fishing, pemanfaatan satwa yang dilin- ikanan tangkap. Berdasarkan hasil wawancara dungi oleh masyarakat, penambangan pasir, dengan nelayan, nelayan selalu menemukan keterbatasan sumber daya baik manusia.

Persamaan persepsi antara agen dan aktor yaitu menyadari masih kurang maksimalnya monitoring pada kawasan konservasi $\mathrm{se}_{-}$ hingga pemerintah perlu meningkatkan lagi kerjasama antara agen dan aktor seperti Dinas Kelautan Perikanan (DKP), Balai Taman Nasional Wakatobi (BTNW), TNI AL, Pokmawas dan pemerintah terlambat mengambil tindakan terhadap penggunaan alat tangkap yang tidak ramah lingkungan, pengambilan karang dan penambangan pasir ilegal sehingga nelayan berpikir tidak ada gunanya untuk melaporkan kasus-kasus pelanggaran kepada pemerintah.

Hasil analisis PCA memperlihatkan perbedaan persepsi antara pemerintah dengan ne

Formatted: Indonesian

Formatted: Indonesian

Formatted: Indonesian

Formatted: Indonesian

Formatted: Indonesian

Formatted: Indonesian

Formatted: Indonesian

Formatted: Indonesian

Formatted: Indonesian

Formatted: Indonesian

Formatted: Indonesian

Formatted: Indonesian

Formatted: Indonesian

Formatted: Indonesian

Formatted: Indonesian

Formatted: Indonesian

Formatted: Indonesian

Formatted: Indonesian

Formatted: Indonesian

Formatted: Indonesian 
layan. Perbedaan yang terjadi karena nelayan merasa pemerintah masih kurang memperhati kan kesejahteraan nelayan. Contohnya adalah bantuan dari pemerintah (DKP dan KKP) yang terkandang tidak tepat sasaran dan hanya untuk orang tertentu namun pemerintah telah merasa memberikan bantuan kepada nelayan berupa alat tangkap, keramba dan mesin.

Gambar 2 memperlihatkan hasil analisis PCA dan menunjukkan perbedaan persepi an tara nelayan dan pemerintah terhadap penge lolaan kawasan konservasi dengan zonasi. Berdasarkan hasil wawancara dengan nelayan bahwa ada beberapa nelayan yang merasa tidak dilibatkan dalam penentuan zonasi sehing ga ada nelayan yang berbeda persepsi dengan pemerintah dalam hal zonasi. Pada kawasan konservasi, zonasi sangat diperlukan dan bebe rapa negara yang telah berhasil dalam kawasan konservasi dengan zonasi (Nikijuluw et al. 2013) adalah

1. Kawasan konservasi perairan Pulau Sumi Ion Filipina; density ikan meningkat 500 ekor/m², tangkapan ikan meningkat dari 14 ton $/ \mathrm{km}^{2}$ menjadi 36 ton $/ \mathrm{km}^{2}$ setelah 10 ta hun pengelolaan.

2. Leigh Marine Reserve New Zealand; kepa datan ikan Pargus auratus mencapai 5,8-8,7 kali lebih besar dibandingkan dengan dae rah di luar Kawasan Konservasi Perairan, pertumbuhan biomassa lobster naik 10,9\% setiap tahunnya, kelimpahan meningkat $9,5 \%$ dan produksi telur meningkat $9,1 \%$

3. Jepang: penutupan Kawasan Konservas Perairan seluas $13,7 \mathrm{~km}^{2}$ selama 4 tahun meningkatkan kelimpahan kepiting (Chionoecetes opilio) sekitar $10-42 \%$.

4. National Marine Sanctuary Florida Keys: peningkatan pendapatan rata-rata nelayan sebesar $67 \%$.

5. Daerah penangkapan Georges Bank yang ditutup seluas $17.000 \mathrm{~km}^{2}$ atau $25 \%$ dar luas fishing ground untuk recovery stok pada tahun 1974, menyebabkan stok ikan yellow tail, flounders, dan haddock mening kat secara signifikan

Pengelolaan pada Taman Nasional Wakatobi perlu dilengkapi dengan peraturan ukuran ikan yang layak tangkap karena selama ini baru UD Pulau Mas yang menerapkan peraturan minimal berat ikan yaitu hanya menerima ikan hidup dengan berat minimal 600 gr. Hal tersebut sesuai dengan Sala (2018) yang menyatakan bahwa saat ini umumnya ukuran minimum yang diterima oleh pasar dalam perdagangan kerapu hidup adalah $0,6 \mathrm{~kg}$ sehingga pemerintah daerah khususnya bupati perlu untuk membuat peraturan ukuran minimal yang tertangkap.

Pengaturan lainnya yang diperlukan adalah pengaturan armada penangkapan ikan. Pengaturan armada diperlukan untuk menjaga kualitas lingkungan, seperti yang dilakukan di Cilacap dalam mengendalikan penambahan kapal yaitu kapal baru diperbolehkan hanya untuk penggantian kapal lama yang sudah tidak beroperasi (Suman dan Satria 2013).

Penangkapan ikan dengan alat yang ti dak ramah lingkungan seperti bom dan bius masih ditemukan di Kabupaten Wakatobi se hingga perlu adanya penegakan hukum. Kondisi ini sesuai dengan hasil temuan Sopari et al. (2014) yang menyatakan bahwa salah sat permasalahan di Kabupaten Wakatobi adalah destructive fishing dan diperlukan patroli/ope rasi pengamanan. Penegakan hukum dalam kawasan konservasi memperhatikan efektivitas koordinasi, kerjasama serta ketaatan terhadap peraturan. Sanksi harus diberlakukan terhadap pelanggar hukum. Adam dan Ade (2013) me nyatakan bahwa yang terpenting dari pengembangan kawasan konservasi laut adalah unsur penegakan hukum harus dilakukan dengah tegas.

Perlu peningkatan keefektifan daerah perlindungan laut (DPL) yang telah dibuat oleh Coral Reef Rehabilitation and Manage ment Program (COREMAP) II dan masyarakat Kabupaten Wakatobi karena DPL memegang peranan bagi pelestarian dan pengelolaan terumbu karang. Peta Sebaran DPL Kabupaten Wakatobi disajikan pada Gambar 4 3. DPL yang efektif di Pulau Wangi-wangi Kabupaten Wakatobi yaitu Desa Waha, Sombu dan Desa Lia tetapi masih ada beberapa DPL yang masih belum efektif seperti desa Matohara karena jauh dari pemukiman penduduk dan pengawas an dari pokmawas, Balai Taman Nasional Wa katobi (BTNW) serta Lembaga Swadaya Masyarakat (LSM). Menurut Westmacott et al. (2000), peningkatan keefektifan daerah perlin dungan laut (DPL) yaitu :

1. Memperbaiki sistem zonasi dan/atau batasan Daerah perlindungan Laut (DPL) seperti menciptakan zona baru atau merubah batasan DPL

2. Tidak diberikan beban tambahan seperti kunjungan wisatawan

3. Kursus-kursus pelatihan untuk para pengelola DPL yang kini tersedia luas
Formatted: German (Germany)

Formatted: Font: Not Bold, German (Germany)

Formatted: Font: Not Bold, German (Germany)

Formatted: German (Germany)

Formatted: Indonesian

Formatted: Indonesian

Formatted: Indonesian

Formatted: Indonesian

Formatted: Indonesian

Formatted: Indonesian

Formatted: Indonesian

Formatted: Indonesian

Formatted: Indonesian

Formatted: German (Germany)

Formatted: German (Germany)

Formatted: Indonesian

Formatted: Indonesian

Formatted: Indonesian

Formatted: Indonesian

Formatted: Indonesian

Formatted: Indonesian

Formatted: Indonesian

Formatted: Indonesian

Formatted: Indonesian

Formatted: Indonesian

Formatted: Indonesian

Formatted: Indonesian

Formatted: Indonesian

Formatted: Indonesian

Formatted: Indonesian

Formatted: Indonesian

Formatted: Indonesian

Formatted: Indonesian

Formatted: German (Germany)

Formatted: German (Germany)

Formatted: Indonesian

Formatted: Indonesian 


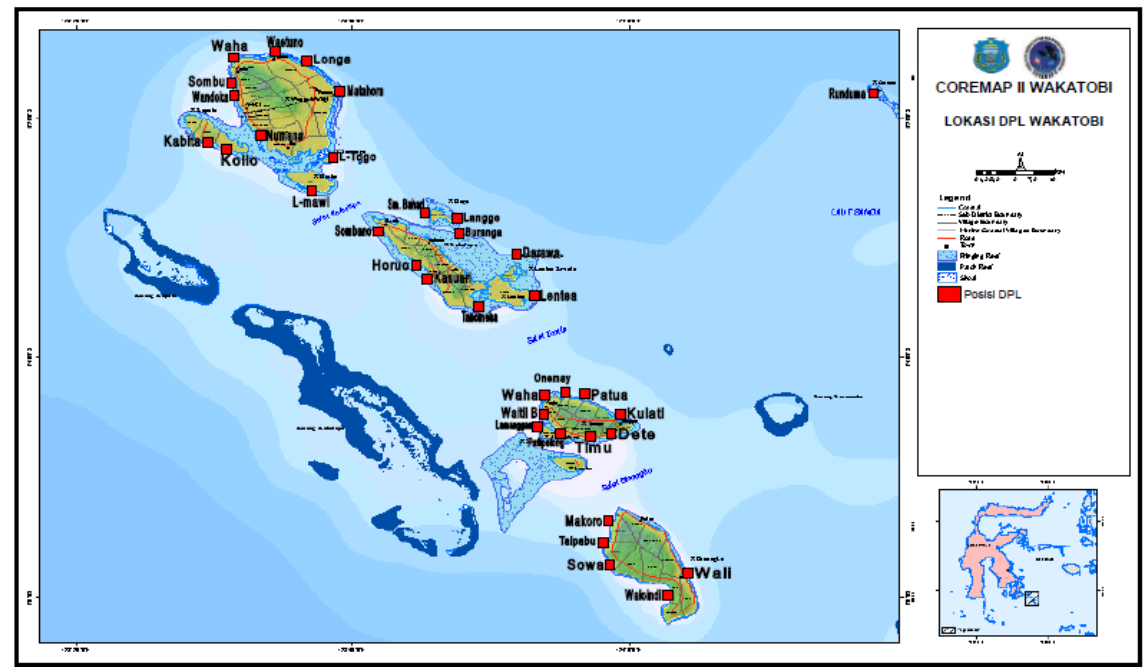

Gambar 3 4_Peta Sebaran Daerah Perlindungan Laut Kabupaten Wakatobi (COREMAP II 2008)

Kearifan adat di Kabupaten Wakatobi memiliki peran dalam kehidupan masyarakat wakatobi sehingga kearifan adat perlu dipertahankan dan diefektifkan. Hal tersebut sesuai dengan Arafah (2010) yang melakukan penelitian kearifan lokal di Kabupaten Wakatobi dan mendapatkan bahwa kearifan lokal memiliki peran ekologis dan sosial, yakni secara kelembagaan relevan dengan nilai-nilai konservasi. Kearifan adat yang ada di Kabupaten Wakatobi perlu tetap dijalankan dan diefektifkan yaitu

1. Ritual laut, ritual tersebut perlu diaktifkan lagi karena dilarang melakukan penangkapan pada waktu pemijahan sehingga dapat memberikan kesempatan kepada ikan untuk bertelur.

2. Sistem buka tutup laut perlu diaktifkan lagi karena kearifan lokal ini dapat memberikan kesempatan kepada ikan untuk berkembang biak. Sistem buka tutup adalah ada wilayah tidak bisa dilakukan penangkapan ikan dan aktivitas lainnya yang didasarkan hasil kesepakatan bersama antara masyarakat.

3. Tuba dikatutuang perlu diterapkan di tempat lain bukan hanya di pulau Hoga karena tuba dikatutuang terdapat peraturan (Hasrawaty 2016) yaitu: (1) melarang penangkapan ikan dalam jumlah berlebih; (2) dilarang menangkap ikan yang sedang bertelur; (3) pelarang-an segala bentuk aktivitas penangkapan; (4) pelarangan pembuangan jangkar karena akan merusak karang di lokasi Tuba; (5) pelarangan penangkapan ikan yang dilindungi sehingga dapat melindungi sumber daya lingkungan dan sumber daya hayati.

Kearifan adat sangat diperlukan di dalam pengelolaan seperti yang dikatakan oleh Adam dan Ade (2013) bahwa sistem pengelolaan adat hampir dijalankan di seluruh Indonesia dan praktek tersebut dipegang dan dijalankan. Selain itu, Sulaiman (2010) menyatakan bahwa pola kearifan lokal umumnya menempatkan kapasitas budaya, sistem pengetahuan dan teknologi, religi, tradisi, dan modal sosial (etika dan kearifan lingkungan, norma-norma dan institusi hukum) sebagai sesuatu yang penting dalam rangka memanfaatkan sumberdaya. Kearifan adat di Kabupaten Wakatobi sesuai dengan prinsip-prinsip kawasan konservasi perairan sehingga dapat diterapkan di kawasan konservasi tetapi kearifan lokal tersebut perlu diimbangi dengan aturan zonasi di Taman Nasional Kabupaten Wakatobi.

Perlu ditingkatkan peran lembaga adat di Kabupaten Wakatobi seperti wilayah penang kapan ikan masyarakat lokal berbasis hak komunal (communal property) yang berarti bahwa masyarakat yang menentukan wilayah pe nangkapan ikan. Sesuai dengan Adam (2012) yang mengatakan bahwa kelembagaan lokal seperti koperasi dan kelompok masyarakat/ nelayan mesti terus diberdayakan dan ditingkatkan peranannya agar mampu memberikan daya guna bagi kesejahteraan masyarakat pesisir.
Formatted: Indonesian

Formatted: Indonesian

Formatted: Indonesian

Formatted: Indonesian

Formatted: Indonesian

Formatted: Indonesian

Formatted: Indonesian

Formatted: Indonesian

Formatted: Indonesian

Formatted: Indonesian

Formatted: Indonesian

Formatted: Indonesian

Formatted: Indonesian

Formatted: Indonesian

Formatted: Indonesian

Formatted: Indonesian

Formatted: Indonesian

Formatted: Indonesian

Formatted: Indonesian 
Hak komunal ini dapat diterapkan di pu lau Wangi-wangi karena pulau tersebut mempunyai lembaga adat yaitu kadie Liya, Wanci, Mandati dan Kapota. Berbasis hak komunal diterapkan di Maluku yaitu sasi laut. Masyarakat adat di Maluku dapat mengklaim perairan laut pada periode waktu tertentu sebagai hak eksklusif (exclusion right) dengan cara melarang masyarakat luar memasuki areal sasi (Latuconsina 2009)

Sistem hukum adat dapat diterapkan da lam pengelolaan perikanan karena akan dapat memberikan dampak yang positif ke lingkungan. Menurut Puspita (2017), sistem pengelolaan lingkungan dengan sistem adat sangat bagus dan terbukti cukup berhasil untuk diterapkan karena dasar dari sistem hukum adat laut ini adalah kesadaran dan kepedulian yang mendalam dari masyarakat atas lingkungan sekitar mereka yang telah memberikan banyak keuntungan dan manfaat demi keberlangsung an hidup mereka.

\section{KESIMPULAN}

Berdasarkan hasil penelitian dapat disimpulkan bahwa agen adalah pemerintah (Bala Taman Nasional Wakatobi (BTNW), Kementerian Kelautan dan Perikanan (KKP), Dinas Ke lautan dan Perikanan (DKP) dan Pemerintah Daerah (PEMDA) sedangkan aktor terdiri dar Lembaga Swadaya Masyarakat (LSM), nelayan dan restoran. Persamaan perspektif antara agen dan aktor adalah kawasan konservasi memberikan manfaat bagi masyarakat di Kabupaten Wakatobi. Selain itu terdapat perbedaan antara agen dan aktor yaitu peraturan-peraturan pemerintah yang masih belum lengkap se perti belum, adanya peraturan tentang ukuran ikan yang layak tangkap dan pengaturan arma da penangkapan ikan sesuai daya dukung lingkungan.

\section{SARAN}

Beberapa saran yang bisa dikemukakan berkaitan dengan hasil penelitian ini antara lain perlu dilengkapi peraturan ikan tentang ukuran ikan yang ditangkap. Perlu pengaturan armada penangkapan ikan sesuai daya dukung lingkungan. Pengektifan daerah perlindugan laut karena memberikan dampak yang positif untuk lingkungan seperti terumbu karang. Kearifan lokal seperti ritual laut, sistem buka tutup dan Tuba dikatutuang perlu dilestarikan.

\section{DAFTAR PUSTAKA}

Adam $L_{2}$ Ade S . 2013. Kebijakan Pengem bangan Perikanan Berkelanjutan Di Indonesia. Jurnal Ekonomi dan Kebijakah Publik. 4(2): 195-211

Adam L. 2012. Kebijakan Pengembangan Perikanan Berkelanjutan (Studi Kasus : Kabupaten Wakatobi, Provinsi Sulawesi Tenggara dan Kabupaten Pulau Morotal, Provinsi Maluku Utara). Jurnal Perikanap dan Kelautan. II(2): 115-126.

Arafah N. 2010. Kearifan Masyarakat Dalarh Pengelolaan Hutan Kaindea di Pulau Pulau Kecil. AGRIPLUS. 20(03) September 2010. ISSN 0854-0128

[COREMAP II] Coral Reef Rehabilitation and Management Program. 2008. Penyusunan dan Penetapan Daerah Perlindungan Laut (DPL) COREMAP II Kabupaten Wakatobi.

Hasrawaty E. 2016. Peran Kearifan Lokal Suku Bajo dalam Pengelola Kawasan Konservasi di Kabupaten Wakatobi. Sekolah Tinggi Perikanan. Jakarta.

Latueonsina H. 2009. Eksistensi SASI atau Laut dalam Pengelolaan Perikanan Berkelan jutan Berbasis Komunitas Lokal di Maly ku. Jurnal TRITON. 5(1): 63-71

Mujio, Adrianto $L$, Soewardi $K$, Wardianto $Y$. 2016. Analisis Potensi Konflik Pemanfaatan Ruang Kawasan Pesisir : Integra\$i Rencana Tata Ruang Darat dan Pesisir. Jurnal Sosiologi Pedesaan. pp 139-144.

Nikijuluw VPH, Adrianto L, Bengen DG, Sondita MFA, Monintja D, Megawanto R, Koropitan AF, Amin I, Wiryawan B, Kinseng RA, Zulbainarni N, Suryawati SH, Purnd mo AH, Djohani R, Subijanto J. 2013. Coral governance. IPB Press. $511 \mathrm{p}$

Pangalila FPT. 2015. Status Hasil Tangkapan Perikanan Pancing Dasar di Perairan Teluk Buyat. Jurnal IPTEKS PSP. 2(3): 238247.

Puspita M. 2017. Kearifan Lokal dalam PengeIolaan Sumber Daya Pesisir dan Laut Hukum Adat Laot dan Lembaga Panglimá Laot. Researc Gate. Doi:10.14710/sabda.v312.13253.

Ramadhan A, Lindawati, Kurniasari N. 2016 Nilai Ekonomi Ekosistem Terumbu Karang di Kabupaten Wakatobi. Jurnal Sosek KP. 11: 133-146.

Shrestha S, Kazama F. 2007. Assessment of Surface Water Quality Using Multivariate
Formatted

Formatted

Formatted

Formatted

Formatted: Indonesian 
Statistical Techniques: A Case Study of the Fuji River Basin; Japan. Environmental Modelling \& Software. 22: 464- 475.

Sala R. 2017. Model Pengelolaan Perikanan Tangkap Bekelanjutan pada Zona $\mathrm{Pe}_{-}$ manfaatan Tradisonal di Perairan Selatan Pulau Misol Raja Ampat. [Disertasi]. Institut Pertanian Bogor.

Sulaiman. 2010. Kebijakan Pengelolaan Perikanan Berbasis Kearifan Lokal di Aceh. Jurnal Kainun. 50: 176-195.

Sopari H, Ngakan PO, Darmawan S. 2014. Model Kolaborasi Perencanaan Antara Balai Taman Nasional Wakatobi dan $\mathrm{Pe}_{-}^{-}$ merintah Kabupaten WAKATOBI dalam Pengelolaan Sumber Daya Alam Hayati Secara Lestari. J Sains \& Teknologi. 14(2): 189-198

Suman A, Satria F. 2013. Strategi Pengelolaan Sumber Daya Udang Laut Dalam Secara Berkelanjutan di Indonesia. Jurnal Kebijakan Perikanan Indonesia, Pusat Peneli tian Pengelolaan Perikanan dan Konservasi Sumber Daya lkan, Kementerian Ke lautan dan Perikanan, 5(1): 47-55.

Westmacott S, Teleki K, Wells $S$ dan West $J$. 2000. Pengelolaan Terumbu Karang yang Telah Memutih dan Rusak Kritis. IUCN Publications Services UK
Formatted: Indonesian

\begin{tabular}{|l|}
\hline Formatted: Indonesian \\
\hline Formatted: Indonesian \\
\hline Formatted: German (Germany) \\
\hline Formatted: German (Germany) \\
\hline Formatted: German (Germany) \\
\hline Formatted: Indonesian \\
\hline Formatted: German (Germany) \\
\hline Formatted: German (Germany) \\
\hline
\end{tabular}

